\title{
ANACLETO Morones y la ambivalencia del signo
}

\author{
María Teresa Caro
}




\section{Resumen}

El análisis morfológico del cuento de Juan Rulfo (1996) Anacleto Morones, permite evidenciar y analizar la complejidad de las relaciones humanas incluso si estas se establecen entre seres aparentemente simples o básicos como es el caso de los personajes del cuento. Bien podría decirse -usando la terminología de Saussureque Anacleto Morones (el personaje) es un signo cuyo significado es Lucas Lucatero y cuyo significante se encuentra expresado en las Viejas o mujeres de Amula.

Palabras clave: Santo, ambivalencia, signo, significado, significante.

\section{Anacleto Morones And The Sign's Ambivalence \\ Abstract}

A morphological analysis of Juan Rulfo'stale (1996) Anacleto

Morones renders possible to detect and analyze the complexity of human relationships, even if they happen among seemingly simple or basic human beings, as the main characters of thist ale are.

Using Ferdinand de Saussure's terminology, it might be argued that Anacleto Morones (the character) is a sign in which the signified is Lucas Lucatero, while the signifier is expressed through the old women of Amula.

Key words: Holy, ambivalence, sign, signifier, signified.

\section{Anacleto Morones E A Ambivalência Do Signo \\ Resumo}

A análise morfológica do conto de Juan Rulfo (1996) Anacleto Morones deixa enxergar e analisar a complexidades das relações humanas, também se estas se estabelecem entre seres aparentemente simples ou básicos como é o caso dos personagens do conto. Bem poderia se dizer -usando a terminologia de Sasussure- que Anacleto Morones (o personagem) é um signo onde seu significado é Lucas Lucatero e onde seu significativa se encontra expressado em As Velhasou mulheres de Amula.

Palavras Chave: Santo, Ambivalência, Signo, significado, significativa.

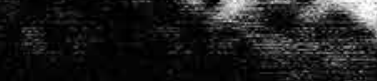

Palawras Chave: Santo, Ambiwalencia, Signo, significado, significativa.

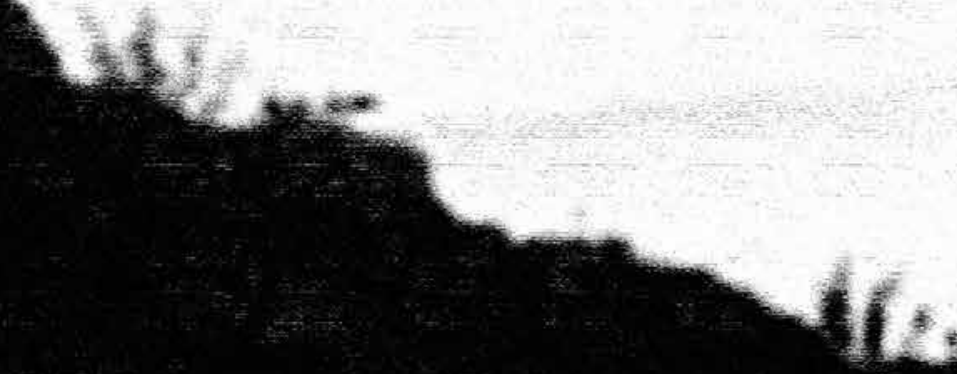


A partir de la selección de algunas de las obras narrativas de las últimas dos décadas, este proyecto consiste en proponer diversos análisis interpretativos llevando hasta sus límites los métodos mismos de análisis literario con el fin de determinar su aplicabilidad al corpus. Así por ejemplo, dado el caso que después de interpretar un análisis narratológico de una novela, las categorías de este tipo de análisis no cumplan papel alguno dentro del texto, se buscará otro tipo de acceso a él habiendo ganado simultáneamente la posibilidad de obtener conclusiones a partir del análisis "fallido". Se tratará entonces de proponer alternativas metodológicas e interpretativas no con el fin de hacer un despliegue de conocimientos teóricos o metodológicos "per ser" sino de tener en cuenta el texto y las posibilidades o imposibilidades que de él surjan.

Además de la reflexión teórica que surgirá de la aplicación de diversos métodos, se tratará de un proyecto teórico en el sentido que interesa realizar un estudio de la heterogeneidad teórica y práctica, bajo las rúbricas de moderno y postmoderno se ocultan, y que llegado el caso o según la situación, salen a relucir como quien saca conejitos o palomas de un sombrero mágico. Se tendrá que realizar una crítica -en el sentido kantiano de poner límites-a estos dos términos o conceptos, primero en general y luego en relación con la literatura latinoamericana y particularmente colombiana de la segunda mitad del siglo. Todo ello, sin embargo, con el fin de comprender -en un sentido gadameriano- un fenómeno literario particular, la creación de ficción -su posibilidad o imposibilidad- en la Colombia fin de siglo y entrever algunas de sus perspectivas futuras.

Como no se pueden establecer semejanzas y diferencias, límites, posibilidades e imposibilidades en el vacío, es necesaria una selección de puntos de referencia a partir de los cuales o contra los cuales se establezcan las posibles relaciones. Toda obra previa o contemporánea podría, en principio asumir este papel, lo que haría el proceso infinito, es decir imposible. Estos puntos de que se habla no son simplemente alusiones o menciones espontáneas. Así, por ejemplo, Rulfo, por razones que expondré en su debido lugar, es a mi juicio uno de tales puntos de referencia. La siguiente es una propuesta interpretativa de análisis de uno de sus cuentos; tal propuesta, sin embargo, no es definitiva ni totalizante, sino que a su vez será afectada por las propuestas del corpus que estudiaré. Lo que quiere decir es que el método general será, como la misma palabra método lo indica, no una serie de reglas fijas o absolutas sino un "estar en camino" continuamente, así que los análisis aunque en algunos casos logren una coherencia y unidad casi autónoma -como creo es el caso de este cuento de Rulfo- no dejarán de ser tentativas en movimiento

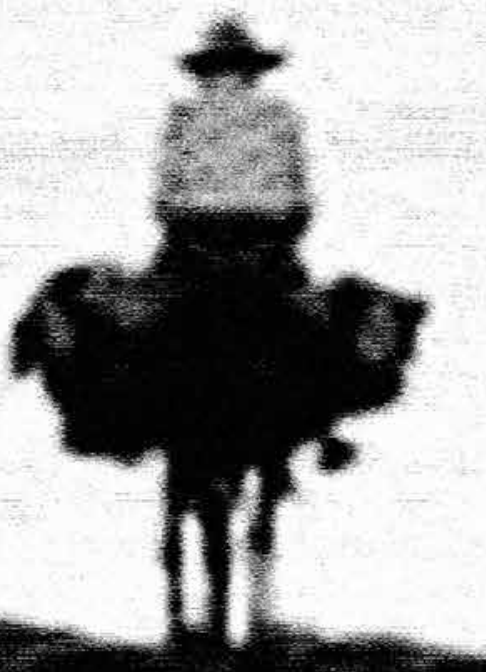


personaje. Con base en los registros del discurso se produce entonces una dinámica de producción, evaluación, y valorización de la información, una dinámica semántica cuyo principio y fin es Anacleto Morones hombre y signo.

¿Quién fue y qué significa Anacleto Morones? Responder a ello solo es posible a partir de y sobre la base del discurso en que consiste el cuento así denominado. El hombre, es decir, el referente del signo lingüístico Anacleto Morones ya no existe. Ciertamente en algún momento de la historia estuvo presente y por lo tanto su presencia puede considerarse como analepsis externa o interna según los límites que se le den a la historia (fábula), pero dicho referente está muerto y enterrado antes de comenzar el discurso y, en la medida en que la relación entre el hombre referente y el signo lingüístico que lo nombra de manera arbitraria -mejor aún, inmotivada- el referente permanecerá ausente y desconocido. Sin embargo desde el título mismo Anacleto Morones está presente, es decir, el nivel del signo lingüístico y su referente ha sido superado -dimensión que debió existir al comienzo de la labor de Anacleto Morones cuando aún era un desconocido con un nombre cualquiera- para dar paso a otro: el del signo literario. De esta manera Anacleto Morones está presente puesto que la relación referente-signo es ahora motivada.

Preguntar ¿quién es Anacleto Morones? es preguntar ¿qué significa Anacleto Morones? Dicho significado será accesible a través de la autodiégesis, con la isocronía de las escenas dialogadas y los respectivos registros del discurso -en tanto significante- que proporciona el discurso.

¿Qué significa Anacleto Morones? Anacleto Morones aparece como un vínculo unificador. Considerado desde un eje sintagmático Anacleto Morones es el término medio de la relación entre Lucas Lucatero y las mujeres de Amula como grupo (no como individuos); "Siéntate aqui enfrente de nosotras para verte y para que nos oigas" (p.174) le dicen las mujeres a Lucas Lucatero con la intención explícita de que él las ayude a realizar una labor común: la canonización de Anacleto Morones (-iQuieres ir con nosotras?/ -iA dónde?/ A Amula. Por eso vinimos. Para llevarte. p.179).

Tanto Lucas Lucatero como las mujeres han tenido contacto directo con Anacleto Morones. Bien puede decirse que, a pesar de las diferencias de opinión o juicios de valor, tal contacto los sitúa en un mismo nivel, los convierte en semejantes, en testigos. En el axis paradigmático que surge del discurso esta semejanza se convierte en diferencia, en oposición, ya que Lucas Lucatero y las mujeres no son dos elementos estáticos y menos aún inconmesurables, incomparables o intraducibles sino dos elementos relacionalmente dinámicos en función de Anacleto Morones. Pero si bien ellos se definen y determinan en términos relativos a Anacleto Morones, este a su vez se manifiesta a partir de tal referencia.

Anacleto Morones es también el término medio de un eje sintagmático temporal. Con base en él se establece un antes y un después. Lucas Lucatero conoció a Anacleto Morones antes de que se "hiciera famoso por sus milagros" (p. 179), las mujeres como para Lucas Lucatero dicho antes y después no presenta cambios sustanciales importantes en relación con lo que fue y por tanto es y será Anacleto Morones -aunque las dos interpretaciones del quién de Anacleto Morones se contradigan.

Para Lucas Lucatero el axis antes y después parece terminar con la desaparición (muerte) de Anacleto Morones, pero aún tiene sus dudas:

Y ahora Pancha me ayudaba a ponerle otra vez el peso de las piedras, sin sospechar que alli debajo estaba Anacleto y que yo hacía aquello por miedo de que se saliera de su sepultura y viniera de nueva cuenta a darme guerra. Con lo mañoso que era, no dudaba que encontrara el modo de revivir y salirse de alli (p.190).

Las mujeres intentan prolongar el axis con un después de la desaparición de Anacleto Morones: "Ahora está en el cielo en cuerpo y alma presentes"(p.182). Una manera explícita de prolongarlo es el proyecto de canonización. Con el testimonio de Lucas Lucatero se podría, por una parte, iniciar el proceso de canonización o de reconocimiento público de la beatitud o santidad de Anacleto Morones, por otra, mantener el vínculo con Lucas Lucatero como representante y continuador de la obra de Anacleto Morones "Esperábamos que tú siguieras su obra. Lo heredaste todo" (p.186).

Con su negativa inicial Lucas Lucatero muestra que no está dispuesto a continuar el axis, que no acepta la versión de las mujeres sobre la santidad de Anacleto Morones. Al aceptar Lucas Lucatero la versión de las mujeres y prometer dar testimonio, la Pancha, representante y líder de las mujeres, corrobora explícitamente la versión proporcionada por Lucas Lucatero: 
Después ella me dijo, ya de madrugada:

- Eres una calamidad, Lucas Lucatero.

No eres nada cariñoso.

¿Sabes quién sí era amoroso con una?

-¿Quién?

-El Niño Anacleto. Él sí que sabía hacer el amor.

De nuevo se restablece el eje sintagmático de semejanza. Anacleto Morones, Lucas Lucatero y las mujeres pertenecen a un mismo sintagma, sea este social, moral, cultural o económico, y conocen sus códigos implícitos o reglas de juego.

Además del vínculo establecido a través de la relación con Anacleto Morones, existieron o existen otros vínculos entre Lucas Lucatero y algunas de las mujeres. Él las conoce a ellas individualmente:

"Yo sabía de dónde eran y quiénes eran; podía hasta haberles recitado sus nombres, pero me hice el desentendido." (p. 172) "Las hijas de Ponciano, de Emiliano, de Crecenciano, de Toribio el de la taberna y de Anastacio el peluquero." (p. 173) "No sabia que tenías marido. ¿No eres la hija de Anastasio el peluquero? La hija de Tacho es soltera, según yo sé." (p. 186).

e incluso, como por ejemplo con la Nieves, hasta en un plano erótico personal. Lucas Lucatero tampoco es un extraño para ellas - "Tú siempre fuiste muy mentiroso y hasta levantafalsos" (p.180).

Nuevamente, ¿qué significa Anacleto Morones? Dos actantes responden a esta pregunta, por una parte, su colega y yerno y, por otra, las mujeres de la Congregación de Amula. Para el primero es el vivo diablo, para las segundas un santo. Estas dos perspectivas se relativizan al indagar por el quién del sujeto que las proporciona. Es decir, hay que preguntar además de quién es Lucas Lucatero, quiénes son las mujeres de la Congregación de Amula.

Anacleto Morones "Él sí que era el vivo demonio" (p.181) afirma Lucas Lucatero. Dentro de un eje paradigmático, a Anacleto Morones corresponde a un nivel inferior en oposición a uno superior que correspondería a la santidad o bien. Entre estos dos hay un término medio, una mezcla humana y ambigüa de bien y mal:"Me queda el consuelo de que Anacleto Morones era peor que yo" (p. 188).

Ser el vivo demonio es ser un hombre hábil, ingenioso, oportunista y manipulador, capaz de aprovechar las situaciones en su propio beneficio, ya sea económica, social, sexualmente, etc. el comienzo de la carrera pública, por ejemplo, muestra cómo Anacleto Morones supo manipular el asombro de la gente:

Entonces él puso los brazos en cruz y comenzó a decir que acababa de llegar de Roma, de donde traía un mensaje y era portador de una astilla de la Santa Cruz donde Cristo fue crucificado.

Yo no más me vivía con la boca abierta, mirándolo engatusar al montón de peregrinos que iba a verlo (p. 182).
Incluso y como ayudante suyo Lucas Lucatero también se benefició con la labor de Anacleto Morones: "le agradezco que me haya matado el hambre, pero eso no quita que él fuera el vivo diablo" (p. 182).

Las implicaciones eróticas llegan hasta lo incestuoso. Lucas Lucatero lo acusa directamente:

Dejó sin vírgenes esta parte del mundo, valido de que siempre estaba pidiendo que le velara su sueño una doncella. (p. 185) -Hacer hijos no es ningún milagro. Ése era su fuerte. (p. 186) Adentro de la hija de Anacleto Morones estaba el hijo de Anacleto Morones (p. 184).

Para las mujeres, por el contrario, en el eje paradigmático, a Anacleto Morones o al "Santo Niño" (p.171)- como ellas lo denominan- corresponde el nivel superior. Es decir, no solo fue un santo sino que merece ser canonizado ("Hemos abierto, todas las congregantes del Niño Anacleto, un novenario de oraciones para pedir que nos lo canonicen" (p. 179).

Como santo ha de estar en el cielo - "Ahora está en el cielo en cuerpo y alma presentes. Y desde allá nos bendice” (p.182)-y mediar entre Dios y sus fieles "Recemos el "Pendiente somos, Señor" para que el Santo Niño interceda por nosotras" (p.182); como santo goza de la devoción de sus fieles - "Y aquellas mujeres se arrodillaron, besando a cada Padre nuestro el escapulario donde estaba bordado el retrato de Anacleto Morones" (p.182).

Según el testimonio de algunas de las mujeres, Anacleto Morones proporcionaba todo tipo de ayuda tanto espiritual como corporal. Todos sus actos son entonces interpretados desde el axis paradigmático del bien y la santidad:

Sólo sus milagrosas manos me arroparon en esa hora en que se siente la llegada del frío. Y le di gracias por el calor de su cuerpo (p.185).

Volví a encontrar a mi padre y a mi madre en él. Se pasó la noche acariciándome para que se me bajara mi pena. (p.185).

La única noche feliz la pasé con el Niño Anacleto, entre sus consoladores brazos (p.186).

El curó a mi marido de la sífilis (p.187).

Si para Lucas Lucatero Anacleto Morones es el vivo diablo, entonces las mujeres, sus seguidoras, serán sus hijas:

¡Viejas, hijas del demonio! Las vi venir a todas juntas, en procesión. Vestidas de negro, sudando como mulas bajo el mero rayo del sol. Las vi desde lejos como si fuera una recua levantando polvo, su cara ya ceniza de polvo. Negras todas ellas (p.171).

En la medida en que Lucas Lucatero se reconoce así mismo como malo, pero no tanto como Anacleto, con una lógica elemental y contundente pregunta si Anacleto Morones es considerado Santo: "Y por qué yo no"? (p.187). Pero según las 
mujeres lo único bueno en Lucas Lucatero es su vínculo con Anacleto Morones, el haber sido ayudante y yerno suyo:

Si no estuviera de por medio que eres el yerno del Santo Niño, no te vendríamos a buscar, contimás te pediríamos nada. Siempre has sido muy diablo, Lucas Lucatero. (p.181).

Ahora consideramos como fonemas las versiones de Lucas Lucatero y de las mujeres respecto a Anacleto Morones. En el Axis paradigmático estos fonemas presentan una oposición -fonológica- binaria y distintiva; es decir, son fonemas opuesto, alternativos y, por lo tanto, excluyentes como lo serían, p. e. los fonemas p y b en las palabras "pas / bas". La elección de uno u otro producirá un cambio de significado de la misma manera que la elección de p o b en el ejemplo anterior. Así pues, como ya se ha señalado, Anacleto Morones significa diablo o santo según se opte por uno u otro fonema.

Desde la focalización interna con la que comienza el discurso, el narrador personaje Lucas Lucatero no solo se distancia de las mujeres, sino que insiste en sus características negativas: las focaliza como un grupo -"Las vi venir a todas juntas, en procesión" (p.171), "y dejar plantada a aquella sarta de viejas canijas" (p.174); un grupo de mujeres que considera viejas, sucias, ignorantes y feas: "y se arrimaron hasta ponerse junto a mí, todas juntas, apretadas como en manojo, chorreando sudor" (p.171) "sudando como mulas" (p.171), "iViejas y feas como pasmadas de burro!” (p.172), "Marchitas como floripondios engarruñados y secos" (p.174). Vistas así, es decir, desde la perspectiva de Lucatero, las mujeres no solo despiertan cierta repulsión, cierto rechazo sino que parecen justificar el que Lucas Lucatero las rechace e incluso desee escapar de ellas: "Tenía pensado no regresar...y dejar plantada a aquella sarta de viejas canijas" (p.174).

Puesto que las mujeres son sus seguidoras, distanciarse de ellas es distanciarse de Anacleto, al menos del Anacleto que según Lucas Lucatero ellas encarnan y que era peor que él (p.188). Ello a su vez será una especie de justificación implícita de su acción, el asesinato del vivo diablo.

Las mujeres también se distancian de Lucas Lucatero, y de todas sus afirmaciones. Gran parte de las escenas dialogadas consiste en no estar de acuerdo con él. Ellas en tanto seguidoras del Santo Anacleto Morones no podrán explícitamente aceptar el elemento negativo que representa Lucas Lucatero. De lo contrario tendrían que aceptar al Anacleto representado por Lucas Lucatero, tan alejado de una posible canonización, lo que a su vez invalidaría su acción o función, la canonización del santo.

Sin embargo, en un axis sintagmático, sin ser fonemas idénticos, las dos versiones del signo Anacleto Morones no representan una oposición excluyente sino relacional. Es decir, los fonemas son diferentes pero conforman una y no otra palabra. La relación fonemas significado es ahora complementaria en función del sintagma. A pesar de la diferencia entre las dos versiones de la significación del signo Anacleto Morones -diablo o santo- aparece ahora, por una parte, la ecuación Anacleto igual a las mujeres y, por otra, Anacleto diferente de Lucas Lucatero.

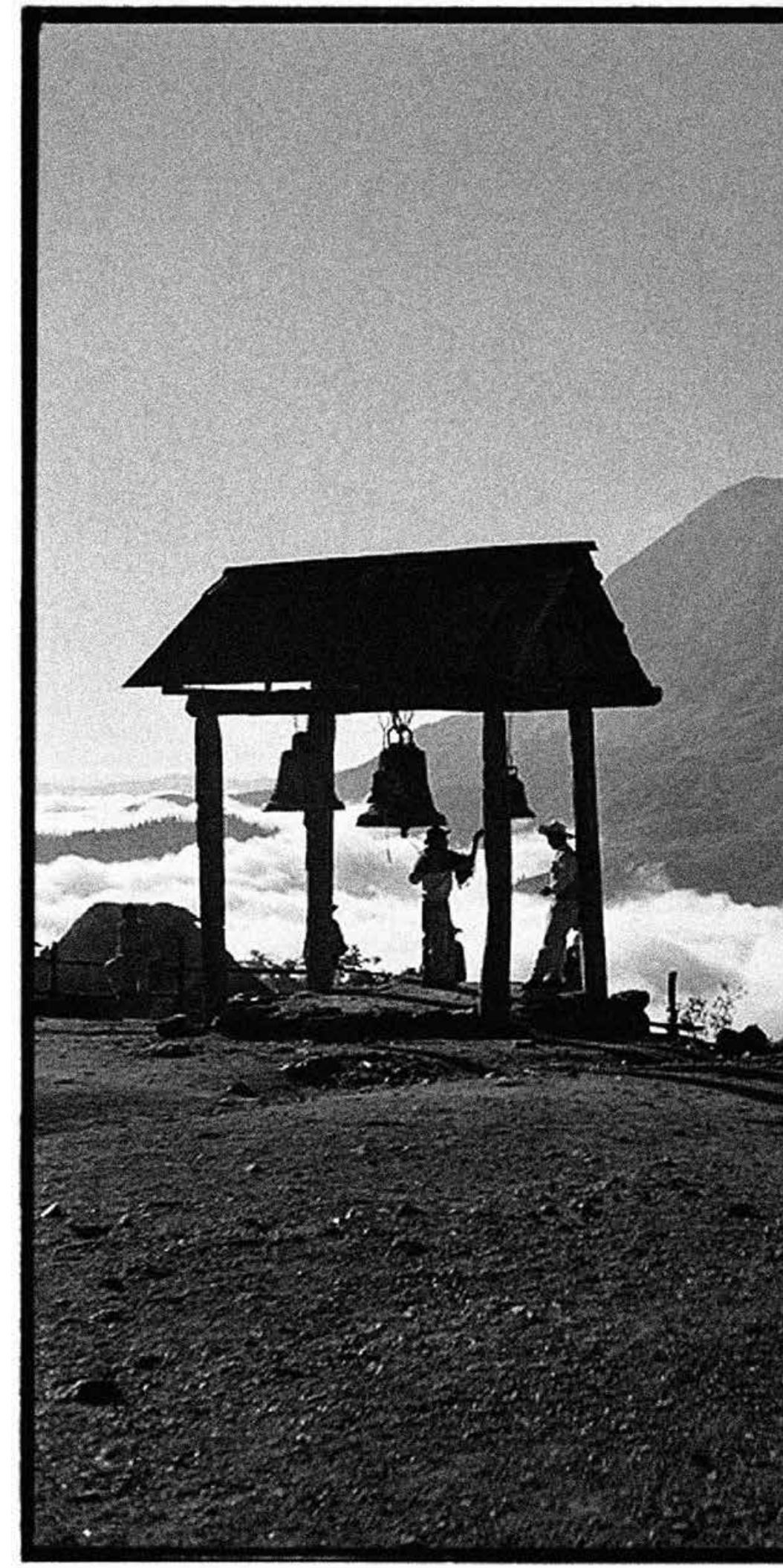


presencia de Anacleto en la vida y destino de Lucatero: "-iPor qué no te llevas a tu hija?- le dije yo-. Eso es lo único que me sobra de todo lo que tengo y dices que es tuyo”. (p.189). Y por esta razón es indispensable que no solo Anacleto sino su hija desaparezcan:

\author{
-Ya no tengo mujer. \\ -¿Luego la tuya? ¿La hija del Niño Anacleto? \\ -Ya se me fue. La corrí.
}

Pero, como lo descubrirá Lucas Lucatero, el vínculo con Anacleto no desaparecerá con su muerte y la ausencia de su hija. Sobre la base del vínculo familiar, que proporciona la consanguinidad padre-hija y que en cuanto yerno incluye a Lucas Lucatero, y, en la medida en que Anacleto Morones fue para las mujeres como un padre y como un hijo, se crea un vínculo familiar no consanguíneo entre Lucatero y las mujeres, una especie de familia política. Ya se ha mencionado que algunas de ellas como individuos y no como grupo conocían y habían tenido algún tipo de relación con Lucas Lucatero, pero es el vínculo como madres e hijas de Anacleto Morones lo que les proporciona la cercanía y confianza de parientes con respecto a Lucas Lucatero, a tal intimidad alude el estar tan adentro:

Yo estaba acuclillado en una piedra, sin hacer nada, solamente sentado alli con los pantalones caidos, para que ellas me vieran asi y no se me arrimaran. Pero sólo dijeron “iAve María Purísima!”. Y se fueron acercando más (p.171).

No nos figuramos que estabas tan adentro; no en este lugar ni en estos menesteres (p.172).

Resumiendo, si Lucas Lucatero es diferente de Anacleto Morones, lo contrario también es válido, Lucas Lucatero es igual a Anacleto. Es decir, Lucatero solo puede distanciarse de Anacleto Morones como de su otro yo. Puede negarlo, ocultarlo, tratar de aniquilarlo, aceptarlo, pero en tanto (Alter) Ego vivirá mientras Lucas Lucatero viva. En este sentido se explican tanto el temor del mismo Lucas Lucatero de que Anacleto se salga de su sepultura, como la esperanza y la exigencia de las mujeres con respecto a Lucatero.

Consideremos ahora el signo Anacleto Morones en términos de significante/ significado con base en las afirmaciones y los comportamientos tanto de las mujeres como de Lucas Lucatero. Si las mujeres de la Congregación de Amula son el significante del signo, dentro de la imagen acústica, santo de este significante, hay otros sonidos. Es decir, junto con la afirmación explícita de la santidad de Anacleto Morones y la intención de su canonización, las mujeres se preocupan por un "qué iría a decir la gente" o un "qué pensaria la gente" lleno de alusiones e insinuaciones eróticas, que se conjuga con convencionalismos morales, fanatismos religiosos y actos groseros.

Todas dijeron que eso sí no, porque qué iría a decir la gente cuando se enteraran de que no habian pasado la noche solitas en mi casa y conmigo alli dentro. Eso sí que no (p.176).

- ¡Ah, cómo serás!, Lucas Lucatero. No se te quita lo hablantín. Ni que estuviéramos tan calientes. (p.175).

-No sigas diciendo cosas, Lucas. Ayer me confesé y tú me estás despertando malos pensamientos y me estás echando el pecado encima (p.177).

A mí también me dan ganas de vomitar -me dijo la Pancha-. Pero me las aguanto. Te tenemos que llevar a Amula a como dé lugar (p. 183).

para yo decirles que pasé la noche ruéguete y ruéguete. Si no, ¿cómo le hago? (p.188).

Así pues a partir de este significante se corrobora entonces el significado del signo que proporciona Lucas Lucatero: Anacleto Morones es el vivo diablo,de lo contrario ¿cómo podría afirmar que la virginidad es un pecado?:

- Hablas con las mismas palabras de Anacleto Morones.

Si el me aconsejó que lo hiciera, para que se me quitara lo hepático. Y me junté con alguien. Eso de tener cincuenta años y ser Anacleto Morones.

-Te lo dijo Anacleto Morones.

-Él me lo dijo, sí. Pero hemos venido a otra cosa; a que vayas con nosotras y certifiques que él fue un santo.

¿Y por qué no yo? (p.187). 
Consideremos ahora a Lucas Lucatero como significante del signo: dentro de la imagen acústica de vivo diablo, hay también otros sonidos. Lucas Lucatero, quien parecía sentir cierta repulsión por estas mujeres: viejas, feas, "Viejas carambas! Ni siquiera una pasadera (...) Ni de dónde escoger" (p.174), es quien le propone a Pancha que pase la noche con él:

-Oye, Francisca, ora que se fueron todas, te vas a quedar a dormir conmigo ¿verdad?

-Pues vámonos convenciendo los dos. Al cabo qué pierdes. Ya estás revieja como para que nadie se ocupe de ti, ni te haga el favor (p.188).

Lucas Lucatero fue además el padre del hijo de la Nieves:

-iNo te acuerdas que fui tu novia? Te esperé y te esperé y me quedé esperando.

¿Cómo dices que te llamabas?

-Nieves.........Me sigo llamando Nieves. Nieves García (p.176).

Y, a diferencia de Anacleto Morones quien no fue asesino, Lucas Lucatero mata y no muestra además ningún remordimiento o arrepentimiento por la acción misma sea ello por cinismo o falta de conciencia moral, dos alternativas presentes por ejemplo en el diminutivo miradita.

Le eché una miradita al montón de piedras que tenía arrinconado en una esquina y le vi la figura de una sepultura (p.175).

Cuando oscureció, ella me ayudó a arreglarle la ramada a las gallinas y a arreglar otra vez las piedras que yo había desparramado por todo el corral, arrinconándolas en el rincón donde habían estado antes (p.189).

-"QQué descanses en paz, Anacleto Morones!", dije cuando lo enterré (p.189).

Así, con base en Lucas Lucatero como significante, se corrobora el significado del signo proporcionado por las mujeres; pues como ya se ha mostrado el significado de "santo" se ha revitalizado dentro de la dinámica significante- significado y de ninguna manera hace referencia a un 'santo' en sentido literal y absoluto. Santo es relativo a las mujeres. Es decir, Anacleto fue un santo porque fue bueno y cariñoso con ellas -dentro de los parámetros y expectativas que mujeres como ellas podían tener. Él descubrió sus necesidades de afecto y atención. Este es el sentido del testimonio que las mujeres esperan de Lucatero: "señalar las obras de misericordia" que realizó Anacleto Morones - para con ellas y por ello ellas, "las viejas de la Congregación de Amula", "eran las únicas que podían tener algún interés en Anacleto Morones" (p.175). Según ellas, Maldosos son todos aquellos que incapaces de ver en las obras de Anacleto, su misericordia, lo acusan de: "abusionero y de brujo y de engaña bobos" (p.178).

La dificultad de responder a la pregunta ¿qué significa Anacleto Morones?, como se ha visto, se presenta en la dinámica semántica en que consiste dicho signo y de la cual son parte activa tanto Lucas Lucatero como las mujeres de la Congregación de Amula, quienes son a la vez significante y significado del signo. Lo cierto es que a pesar de la dinámica misma se llega nuevamente a un equilibrio posible en la medida en que todos los elementos del signo comparten ciertos códigos culturales, morales y lingüísticos que permiten la comunicación.

Este equilibrio restablecido bien podría ilustrarse con las piedras del corral de la casa de Lucas Lucatero. Después de "echarles una miradita" a las piedras que formaban un montón en un rincón de su corral, Lucas Lucatero las esparce "por todas partes", pues, según él, el montón tenía "la figura de una sepultura”; y ciertamente estas piedras formaban el montón sobre la sepultura de Anacleto. Irónicamente será Pancha, la líder de las mujeres, quien lo "ayudará a juntar las piedras" que él "había desparramado por todo el corral, arrinconándolas en el rincón en donde habian estado antes" (p.189).

Con la muerte de Anacleto se ha roto un orden, un equilibrio. Lucatero intenta mantener oculto el asesinato, por ello le preocupa en el nivel de la apariencia que el montón de piedras tenga la figura de una sepultura, pues cabe la posibilidad de que las mujeres también 'vean' esa figura y descubran su crimen. Al desequilibrio o desorden profundo del asesinato corresponde un nivel superficial, el del desorden de las piedras desparramadas y tiradas por todas partes en el corral de Lucatero. A la violencia oculta del asesinato, corresponde la aparente violencia que Lucatero ejerce sobre los conejos, es decir, aquélla está sugerida por esta: “Mataste los conejos? Te vimos aventarles de pedradas" (p.175). Finalmente se produce de 
nuevo un equilibrio y por ello Pancha, como líder representante de las mujeres, ayuda a Lucatero a restablecer el montón de piedras sobre la sepultura de Anacleto: "Échale más piedras, Pancha. Amontónalas en este rincón, no me gusta ver pedregoso mi corral” (p.190). Lucas Lucatero ya no teme a la apariencia, a la figura de una sepultura, y Pancha, ahora Francisca, no vacila en declarar que "El Niño Anacleto. Él sí que sabía hacer el amor” (p.190), y Anacleto Morones podrá ser canonizado gracias al futuro testimonio de Lucas Lucatero. Si Anacleto fue el padre y el hijo, a Lucas corresponderá cumplir la función de espíritu, cerrando así el círculo semántico de una especial Trinidad, tres personas distintas y un solo signo verdadero.

Solo como nota marginal y aunque se trata de dos cuentos distintos y de dos autores diferentes, cabe mencionar que hay ciertos "rastros" de este cuento de Rulfo en el de Gabriel García Márquez (1972) titulado Blacamán por parte del narrador personaje la coincidencia del símil mula -"me pareció una mula de monosabio" (p.83).

Blacamán podría ser considerado signo literario y, en tanto tal, en términos de significante y significado a partir de la focalización interna del narrador personaje y la ausencia de escenas dialogadas. Sin embargo bástenos señalar solo la presencia de algunos de estos rastros.

En ambos cuentos el narrador personaje informa sobre otro con quien durante algún período de su vida compartió 'dichas y desdichas - "Aquélla fue como la mirada del destino, no sólo del mío, sino también del suyo," (p.85) "me compró para siempre" (p.86)- y del que, muerto ya, intenta distanciarse como otro, pero asumiendo sin embargo la misma función o rol del anterior "Así era Blacamán, el malo, porque el bueno soy yo" (p.86). En el cuento de García Márquez el conflicto con el Alter Ego es más directo y complejo; más aún, aparece como la problemática más acentuada, mientras que en el de Rulfo, aunque juegue un papel importante se relativiza en término de las otras problemáticas posibles.

El equilibrio narrativo entre la focalización interna del narrador personaje y las escenas dialogadas de "Anacleto Morones", parece inclinarse en "Blacamán el bueno vendedor de milagros" hacia el polo absoluto, parcializado y subjetivo del narrador personaje y su focalización lo que impide una relativización de la información, de retórica y de discursos indirectos. No en vano la relación con el Alter Ego no aparece como la relación entre dos nombres distintos -como Anacleto y Lucas en el caso del cuento de Rulfo- sino entre dos adjetivos para el mismo nombre: Blacamán; puesto que la distinción entre uno otro no está dada en términos de un sustantivo propio o común sino de un adjetivo calificativo "Asi era Blacamán, el malo, porque el bueno soy yo" (p.86), las fronteras entre uno y otro se diluyen o por lo menos se sitúan dentro del nivel subjetivo psicológico o valorativo.

En "Blacamán el bueno vendedor de milagros" el enfrentamiento y aniquilación del Alter Ego parece presentar niveles más complejos que el simple asesinato de este en "Anacleto Morones". Lo mismo sucede con su posible resurrección.

Mientras en "Anacleto Morones" se encuentra el nivel real del asesinato y el figurado de la alusión a este, sugerido por la pregunta de las mujeres: "¿Mataste los conejos? (p.175); y de manera inversa, el nivel de la certidumbre de la muerte, es decir, de la no-resurrección "Con lo mañoso que era, no dudaba que encontrara el modo de revivir y salirse de alli” (p.190); los niveles de muerte y renacer en el cuento de García
Márquez no pueden distinguirse tan claramente. En el comienzo del cuento hay un incipiente proceso de descomposición y una muerte fingidos (p.84), con el que Blacamán intenta probar la eficacia de su antídoto. Este evento insinúa otras descomposiciones, muertes y resurrecciones. La amenaza de muerte real de los dos individuos por inanición (p.80) precede al violento proceso de descomposición al cual es sometido uno de ellos, el ayudante, y del cual, a través de la función mediadora y activadora de los conejos y de su transposición psicológica y simbólica -"de modo que agarré el cuerpo del conejo por las orejas y lo mandé contra la pared con la ilusión de que era él y no el animal al que se iba a reventar" (p.90)- surgirá el nuevo Blacamán -"así fue como empezó mi vida grande”- quien a su vez causará y asistirá a la muerte real del otro: "desde allí me miró como a una madre y exhaló el último suspiro" "fue ésa la única vez, por supuesto, en que me fracasó la ciencia” (p.94), prefiguración a su vez de la descomposición psicológica, moral y simbólica del mismo, Blacamán el bueno -"y si acaso se ha vuelto a morir lo vuelvo a resucitar, pues la gracia del escarmiento es que siga viviendo en la sepultura mientras yo esté vivo, es decir, para siempre" (p.94). Muerte, descomposición y vida son entonces momentos de un ciclo psicológico, social y simbólico ininterrumpido.

En ambos cuentos en el nuevo ciclo se repite lo que se ha eliminado y se mantiene la misma estructura Lucas Lucatero se irá convirtiendo en Anacleto, Blacamán el bueno es la versión potencializada de Blacamán el malo, capaz de convertir en una productiva industria el negocio de Blacamán el malo.

\section{Referencias}

García Márquez, G. (1972). Blacamán el bueno vendedor de milagros en La increíble y triste historia de la cándida Eréndira y de su abuela desalmada, Barcelona: Barral editores.

Rulfo, J. (1996). Anacleto Morones en El Llano en Llamas. México: FCE colección popular.

\section{María Teresa Caro}

mariatcaro@gmail.com,mariatcaro@hotmail.com

Filósofa de la Universidad de los Andes, Bogotá, Colombia. Máster (M.A.) en Literatura Alemana de la Universidad de Maryland, EE.UU. Doctora en Filología Hispánica de la Universidad de ELTE, Budapest, Hungría. Co-fundadora de la revista de poesía ULRIKA. Libros de poemas publicados: Vestigios; Conjuraciones y blasfemias; Silencios y destellos. Profesora Universitaria y poeta. Actualmente se desempeña como Coordinadora del área de Humanidades de la Escuela Colombiana de Ingeniería.

Artículo recibido en enero de 2012 y aceptado en marzo de 2012. 


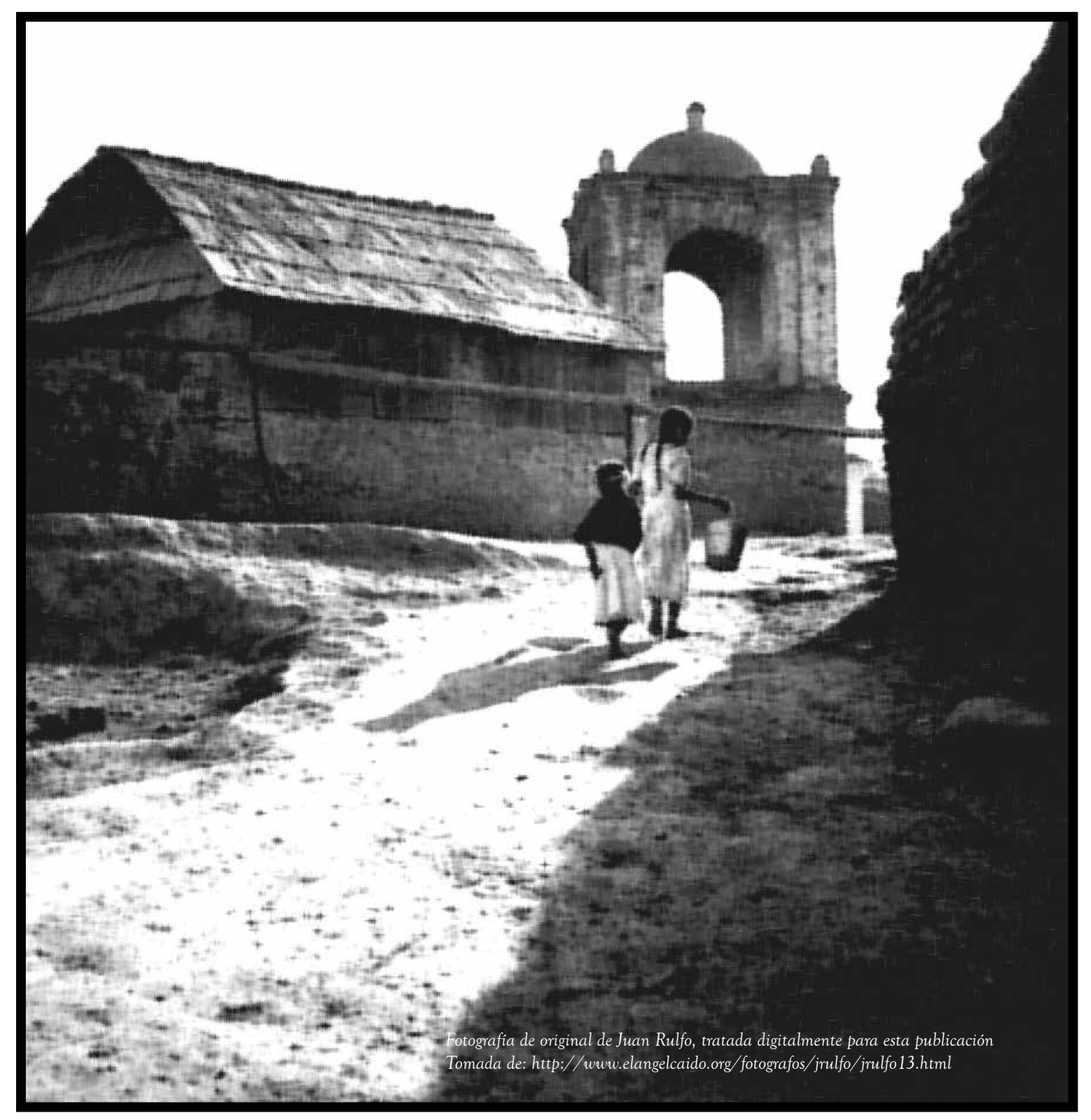

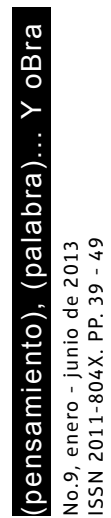

